\title{
Overexpression of AtSZF2 from Arabidopsis Showed Enhanced Tolerance to Salt Stress in Soybean
}

\author{
Mi-Jin Kim ${ }^{1 \dagger}$, Hye Jeong Kim ${ }^{2 \dagger}$, Jung Hun Pak ${ }^{2}$, Hyun Suk Cho ${ }^{2}$, Hong Kyu Choi ${ }^{2}$, Ho Won Jung ${ }^{2}$, Dong Hee Lee, \\ Young-Soo Chung ${ }^{2} *$ \\ ${ }^{1}$ Biotechnology Institute, Nongwoo Bio Co., LTD, Yeoju 49315, Korea \\ ${ }^{2}$ Department of Genetic Engineering, College of Natural Resources and Life Science, Dong-A University, Busan 12655, Korea \\ ${ }^{3}$ Genomine Advanced Biotechnology Research Institute, Genomine Inc., Pohang 37668, Korea
}

\begin{abstract}
Plants have adapted to environmental challenges by expressing many plant genes in response to the stresses. Among those genes, $\mathrm{CCCH}$ zinc finger proteins are involved in abiotic and biotic stresses. Transgenic soybean plants overexpressing AtSZF2 were produced to investigate that its ectopic overexpression enhanced salt stress tolerance by Agrobacterium-mediated transformation using half-seed explants. Sixteen transgenic lines were chosen to analyze for T-DNA insertion and transcription levels, and most of them were confirmed as positive. In further analysis with Southern blot, stable transformation event and copy number were confirmed. Following high salinity stress on the detached leaf and whole plant of two transgenic lines (\#4 and \#6) revealed that the ectopic expression of $A t S Z F 2$ was correlated with stress tolerance in phenotype, ion leakage and chlorophyll content with statistical significance. In another test with $20 \%$ PEG treatment, similar tolerance of transgenic plants was observed with lower ion leakage and higher chlorophyll content, indicating that the damage of cell membrane was prevented in transgenic plants. Finally, expression of various abiotic stress-responding genes was detected by reverse transcriptase and quantitative real-time PCR analysis with the transgenic plants. It could be proposed that introduction of AtSZF2 resulted in the modulation of ABA/stress responsive gene expression in transgenic soybean plants and make them tolerant against salt stress. Considering soybean as a salt-sensitive crop and importance of salt stress tolerance in specific farming region, the introduction of AtSZF2 may provide an approach for crop improvement in soybean breeding.
\end{abstract}

Keywords Soybean, AtSZF2, Agrobacterium-mediated transformation, Salt stress, Ion leakage, Chlorophyll content

\section{INTRODUCTION}

Due to their immobility, plants are exposed to environmental stresses including soil salinity, drought and cold temperatures. Salinity stress represents one of the most consequential environmental factors reducing the quantity and quality of agricultural product (Flowers 2004; Munns and Tester 2008). When grown under the high salinity condition, plants are adversely affected in every aspect of plant physiology and metabolism such as homeostasis disruption and ionic toxicity. However, plants have adapted to environmental challenges by expressing many plant genes in response to the stresses. The cellular and molecular mechanism of plants to abiotic stresses have been studied by many research groups (Shinozaki and Yamaguchi-Shinozaki 2000; Hasegawa et al. 2000; Xiong et al. 2002; Zhu 2002; Shinozaki et al. 2003; Tester and Davenport 2003; Zhu 2003; Sun et al. 2007; Munns and Testter 2008). In those studies, many abiotic stress-inducible transcription factors have been identified, and their functions have been characterized.

Zinc finger motifs consist of cysteines and/or histidines

Received February 3, 2017; Revised February 7, 2017; Accepted February 7, 2017; Published March 1, 2017

*Corresponding author Young-Soo Chung, chungys@dau.ac.kr, Tel: +82-51-200-7510, Fax: +82-51-200-6536

${ }^{\dagger}$ These authors contributed equally to this work as co-first author. 
which coordinate a zinc ion to form local peptide structures that are required for specific biological functions. $\mathrm{CCCH}$-type zinc finger proteins belonging to zinc finger protein family contain tandem zinc-binding motifs characterized by three cysteines followed by one histidine (CX78CX5CX3H; X represents any amino acid) (Miller et al. 1985; Hall 2005). CCCH-type zinc finger proteins role as DNA-binding transcription factors. However, most of CCCH-type zinc finger proteins have shown to be associated with RNA metabolism by directly binding to RNA targets (Bai and Tolias 1996; Carballo et al. 1998; Lai et al. 2006; Hurt et al. 2009). In addition, some CCCH zinc finger proteins are involved in abiotic and biotic stresses. For instance, GHZFP1, a CCCH-type zinc finger protein from cotton, was found to enhance tolerance to salt stress and resistance to fungal disease in transgenic tobacco (Guo et al. 2009). Oxidation-related Zinc Finger 1 (AtOZF1) and salt stress-inducible zinc finger protein 1 (AtSZFl) and $A t S Z F 2$ were involved in regulating the resistance of Arabidopsis plants to oxidative and salt stress response, respectively (Sun et al. 2007; Huang et al. 2011).

Soybean (Glycine max [L.] Merr.) is an important crop providing proteins and vegetable oils and its yield is negatively influenced by a variety of environmental conditions. High salt is one of the abiotic stresses that causes negative effects on plant growth and agronomic traits that significantly reduce the yield of soybean. Improvement of resistance of the crop to abiotic stress through traditional breeding technology requires a lot of time and efforts. The genetic transformation technique provides a powerful tool for overcoming abiotic stress of many species. (Gelvin 2005; Phang et al. 2008; He et al. 2010; Zhang et al. 2010; Bhuiyan et al. 2011; Li et al. 2011; Subramanyam et al. 2011; Movahedi et al. 2012; Yarra et al. 2012). Soybean transgenic plants with multiple functions have been developed using Agrobacterium-mediated transformation system based on the cotyledonary-node (CN) method (Hinchee et al. 1988) and improved by using half-seed explants (Paz et al. 2006). The trials with additional treatments including the mixture of thiol compounds, sonication and vacuum have elevated transformation efficiency to much higher level (Meurer et al. 1998; Olhoft et al. 2003; Kim et al. 2012; Kim et al. 2013;
Kim et al. 2016). With the high transformation rate, various genes could be introduced into soybean to investigate any physiological change or to achieve agronomical improvement. The improvement of salt tolerance is significantly important in crop breeding (Kim et al. 2015; Kwon et al. 2015).

In this study, we produced transgenic soybean plants overexpressing AtSZF2 and confirmed that its ectopic overexpression enhanced salt stress tolerance, compared to wild type plants.

\section{MATERIALS AND METHODS}

\section{Vector construction and Agrobacterium preparation}

An AtSZF2 cDNA open reading frame was amplified from its original vector by using AtSZF2-F primer (5'-CACCATGTGCGGTGCAAAGAGCAACC-3') and AtSZF2-R primer (5'-TTATGCCACAATCTGCTGCTCAT-3'). The original vector was provided by Dr. Dong-Hee Lee (Genomine, Korea) and the resulting PCR products were cloned to $\mathrm{pENTR/D-TOPO}$ vector (Invitrogen, Carlsbad, CA, USA) yielding pENTR-AtSZF2.

The entry vector ( $\mathrm{pENTR}-A t S Z F 2$ ) reacted with the destination vector pB2GW7.0 (VIB-Ghent University, Ghent, Belgium; Karimi et al. 2002) and LR clonase (Invitrogen) yielding pB2GW7.0-AtSZF2. The resultant plasmid was transferred into Agrobacterium tumefaciens strain EHA105 for soybean transformation and subsequently cultured on solid YEP media containing $25 \mathrm{mg} / \mathrm{L}$ rifampicin and $50 \mathrm{mg} / \mathrm{L}$ spectinomycin at $28^{\circ} \mathrm{C}$ for 2 days. Single colony was chosen and grown in $20 \mathrm{~mL}$ liquid YEP medium containing $25 \mathrm{mg} / \mathrm{L}$ rifampicin and $50 \mathrm{mg} / \mathrm{L}$ spectinomycin at $28^{\circ} \mathrm{C}$ for a day until $\mathrm{OD}_{600}$ reached between 0.6 and 0.8. Agrobacterium competent cells for plant transformation were prepared by mixing actively growing Agrobacterium harboring pB2GW7.0-AtSZF2 with equal volumes of $30 \%$ glycerol. Aliquots of competent cells were frozen and kept at $-70^{\circ} \mathrm{C}$ until used.

\section{Soybean transformation}

Mature Korean soybean seeds (Glycine $\max$ L. cv. Kwangankong) were utilized in Agrobacterium-mediated 
transformation experiments. For seed preparation, soybean seeds were surface-sterilized for 20 hours using chlorine gas produced by mixing $5 \mathrm{~mL}$ of $12 \mathrm{~N} \mathrm{HCl}$ and $95 \mathrm{~mL}$ of $12 \%$ sodium hypochlorite. One day before the inoculation, seeds were soaked in sterile distilled water for about 20 hours at room temperature. Previously prepared Agrobacterium competent cell was cultured in $200 \mathrm{~mL}$ of liquid YEP media containing $25 \mathrm{mg} / \mathrm{L}$ rifampicin and $50 \mathrm{mg} / \mathrm{L}$ spectinomycin for nearly 20 hours until $\mathrm{OD}_{600}$ value reached between 0.6 and 0.8. The Agrobacterium culture was centrifuged for 15 minutes at $20^{\circ} \mathrm{C}, 7000 \mathrm{rpm}$. The cell pellet was re-suspended in $5 \mathrm{~mL}$ and $15 \mathrm{~mL}$ liquid co-cultivation medium (CCM) containing $0.32 \mathrm{~g} / \mathrm{L}$ B5 salts with $\mathrm{B} 5$ vitamins, 4.26 $\mathrm{g} / \mathrm{L}$ MES, $1.67 \mathrm{mg} / \mathrm{L}$ 6-BA, $0.25 \mathrm{mg} / \mathrm{L} \mathrm{GA}, 0.2 \mathrm{mM}$ acetosyringone, $3.3 \mathrm{mM}$ L-cysteine, $1.0 \mathrm{mM}$ sodium thiosulfate, $1.0 \mathrm{mM}$ DDT and 3\% sucrose, $\mathrm{pH} 5.4$. The cell pellet re-suspended in $5 \mathrm{~mL}$ liquid $\mathrm{CCM}$ was used as the dipping solution. A longitudinal cut along the hilum of seed was made to separate the cotyledons, and the seed coat was removed. The embryonic axis was excised to obtain the half-seed explants. The embryonic axis of explants was wounded seven or eight times using a No. 11 scalpel blade (Feather, Japan) with the $5 \mathrm{~mL}$ of the concentrated Agrobacterium suspension for dipping treatment. All of the inoculated explants were immersed in $15 \mathrm{~mL}$ Agrobacterium suspension, treated with sonication for 20 seconds and vacuum for 30 seconds. After 30 min of inoculation, cotyledons were placed adaxial side down on CCM solidified with $4.8 \mathrm{~g} / \mathrm{L}$ agar overlaid with filter paper. The co-cultivation continued for 5 days at $24^{\circ} \mathrm{C}$. After 5 day of co-cultivation, the explants were completely washed in liquid shoot induction medium (SIM) containing $3.2 \mathrm{~g} / \mathrm{L}$ B5 salt with B5 vitamins, $0.6 \mathrm{~g} / \mathrm{L}$ MES, $1.67 \mathrm{mg} / \mathrm{L}$ 6-BA, $250 \mathrm{mg} / \mathrm{L}$ cefotaxime, $50 \mathrm{mg} / \mathrm{L}$ vancomycin, $100 \mathrm{mg} / \mathrm{L}$ ticarcillin and 3\% sucrose, $\mathrm{pH}$ 5.6. The explants were subsequently embedded in solid SIM with flat side up. After 2 weeks, explants were transferred to fresh SIM containing $10 \mathrm{mg} / \mathrm{L}$ DL- phosphinothricin (PPT). After 14 days of culture on SIM with PPT, explants were transferred to shoot elongation medium (SEM) containing $4.4 \mathrm{~g} / \mathrm{L}$ MS salt with $\mathrm{B} 5$ vitamins, $0.6 \mathrm{~g} / \mathrm{L}$ MES, $50 \mathrm{mg} / \mathrm{L}$ asparagine, $100 \mathrm{mg} / \mathrm{L}$ pyroglutamic acid, $0.1 \mathrm{mg} / \mathrm{L}$ IAA, $0.5 \mathrm{mg} / \mathrm{L}$ GA3, $1 \mathrm{mg} / \mathrm{L}$ zeatin riboside, $250 \mathrm{mg} / \mathrm{L}$ cefotaxime, 50 $\mathrm{mg} / \mathrm{L}$ vancomycin, $100 \mathrm{mg} / \mathrm{L}$ ticarcillin, $5 \mathrm{mg} / \mathrm{L}$ PPT and $3 \%$ sucrose, $\mathrm{pH}$ 5.6. Selection during the shoot elongation stage was carried with $5 \mathrm{mg} / \mathrm{L}$ PPT, and the explants were transferred to fresh SEM every 14 days. Elongated shoots were cut and dipped in sterile $1 \mathrm{mg} / \mathrm{L}$ IBA for 3 minutes and then transferred to rooting medium containing $4.4 \mathrm{~g} / \mathrm{L}$ MS salt with B5 vitamins, $0.6 \mathrm{mg} / \mathrm{L}$ MES, $25 \mathrm{mg} / \mathrm{L}$ asparagine, $25 \mathrm{mg} / \mathrm{L}$ pyroglutamic acid, $50 \mathrm{mg} / \mathrm{L}$ cefotaxime, $50 \mathrm{mg} / \mathrm{L}$ vancomycin, $50 \mathrm{mg} / \mathrm{L}$ ticarcillin and 3\% sucrose, $\mathrm{pH} 5.6$. Rooted plantlets were transplanted in small pots containing the mixture of soil and vermiculite. The plants $\left(\mathrm{T}_{0}\right)$ were grown in small pots for $1-3$ weeks at $24^{\circ} \mathrm{C}, 18$ hours photoperiod with acclimation procedure and transferred to big pots in greenhouse. $T_{0}$ plants with two trifoliates were screened using an herbicide paint assay to identify putative transformants that expressed the Bar gene. The upper surface of a leaf was treated with $100 \mathrm{mg} / \mathrm{L}$ PPT using a small brush. The response to the herbicide was observed at 3-5 days after PPT application. The PPT-resistant $T_{0}$ plants were grown in the greenhouse until maturity, and $\mathrm{T}_{1}$ seeds were harvested.

\section{Genomic DNA analysis of transgenic plants}

Genomic DNA was extracted from leaf tissues of $T_{0}$ soybean plants using the cetyltrimethylammonium bromide. The polymerase chain reaction (PCR) was performed with KOD FX polymerase (TOYOBO, Japan) and two primer sets were designed in the regions of AtSZF2 (5'-GCAGACGGGTCGGGTCTAAGAAGA-3'/5' - CTTGTCTCTACTCGCTGCACCATT- $\left.3^{\prime}\right)$ and Bar (5'-CATGTAATGCTGCTCAAGGTACGC-3'/5' -CATGTAATGCTGCTCAAGGTACGC-3') to amplify the DNA fragments of $1538 \mathrm{bp}$ and $550 \mathrm{bp}$ in size, respectively. To confirm the introduction of T-DNA insertion into plant genome, additional primers were prepared to amplify the both end regions of vector constructs: for DNA from left board (LB) to $\mathrm{Bar}, 5^{\prime}$-TGGCTGGTGGCAGGATATATTGTG-3'/5' -AGACAAGCACGGTCAACTTCCGTA-3', and for DNA from AtSZF2 to right board (RB), 5'- CAGTCTCCTGAGATGTCTGTTATG-3' $/ 5^{\prime}$-TTAAACTGAAGGCGGGAAACGACA-3'. PCRs were performed with the same KOD FX polymerase to generate 862 bp and $1310 \mathrm{bp}$ amplified products, respectively. 
For Southern blot analysis, three micrograms of the genomic DNA from both the non-transgenic (NT) and $\mathrm{T}_{1}$ transgenic soybean plants were digested overnight with restriction enzymes, fractionated on $0.8 \%$ agarose gel, alkaline-transferred onto Hybond $\mathrm{N}+$ nylon membranes (Amersham Pharmacia, USA), and probed using biotin-labeled TPSP and soybean AtSZF2 gene probes. DNA probe preparation was conducted with the Nick Translation System (Invitrogen), in accordance with the manufacturer's instructions. The biotin-labelled DNA was then detected via chemiluminescence using streptavidin alkaline phosphatase and CDP-Star ${ }^{\mathbb{R}}$ (Applied Biosystems, Bedford, MA). Hybridization, membrane washing and detection were all conducted in accordance with the manufacturer's instructions.

\section{RNA analysis of transgenic plants}

Total RNAs were isolated from both the non-transgenic and transgenic $\mathrm{T}_{0}$ soybean plants using Plant RNA Purification Reagent (Invitrogen) according to the manufacturer's instructions. Reverse transcriptase-PCR
(RT-PCR) was performed using SuperScript ${ }^{\mathrm{TM}}$ One-Step RT-PCR with Platinum ${ }^{\circledR}$ Taq (Invitrogen) as the manufacturer's instruction. The primer pairs used in the RT-PCR are presented in Table 1. For an internal control to normalize the amount of leaf RNAs, $18 S$ rRNA was used.

Quantitative real-time PCR (qRT-PCR) was performed in 96-well plates with the CFX-96 ${ }^{\mathrm{TM}}$ Real-Time system (Bio-Rad, Hercules, CA, USA). First-strand cDNA was synthesized using Superscript ${ }^{\mathrm{TM}}$ II Reverse Transcriptase (Invitrogen) and oligo-dT (Invitrogen), following the user manual. The quantity and quality of the synthesized cDNA were determined by a spectrophotometer. To reduce systematic error from variation of cDNA quantity for PCR, all cDNA samples were diluted to $3 \mathrm{ng} / \mu \mathrm{L}$ and stored at $-20^{\circ} \mathrm{C}$ until used. Each reaction contained $3 \mu \mathrm{L}(3 \mathrm{ng} / \mu \mathrm{L})$ of cDNA, $0.2 \mu \mathrm{L}(10 \mathrm{pm} / \mu \mathrm{L})$ of each primer, and $10 \mu \mathrm{L}$ SYBR $^{\circledR}$ Premix Ex Taq ${ }^{\text {TM }}$ (TAKARA, Japan) in a total reaction volume of $20 \mu \mathrm{L}$. The PCR conditions were $95^{\circ} \mathrm{C}$ for 3 minutes, 40 cycles of 10 seconds at $95^{\circ} \mathrm{C}, 10$ seconds at $55^{\circ} \mathrm{C}$ and 20 seconds at $72^{\circ} \mathrm{C}$, followed by the generation of a dissociation curve by increasing temperature from $65^{\circ} \mathrm{C}$

Table 1. Gene-specific primers used for RT-PCR.

\begin{tabular}{|c|c|}
\hline Gene name & Primer sequence $\left(5^{\prime}\right.$ to $\left.3^{\prime}\right)$ \\
\hline \multirow[t]{2}{*}{ AtSZF2 (AT2G40140) } & Forward: GCAGACGGGTCGGGTCTAAGAAGA \\
\hline & Reverse: CTTGTCTCTACTCGCTGCACCATT \\
\hline \multirow[t]{2}{*}{ Bar } & Forward: CATGTAATGCTGCTCAAGGTACGC \\
\hline & Reverse: CATGTAATGCTGCTCAAGGTACGC \\
\hline \multirow[t]{2}{*}{ GmDREB2 (DQ054363) } & Forward: ATGGAAGAAGCGGGTTTAGGAGAT \\
\hline & Reverse: CTAATCTTCAGGTTTGGGATACTC \\
\hline \multirow[t]{2}{*}{ GmGT-2A (EF221753) } & Forward: AAGAGGAAGCTGACGCAGTTTCTG \\
\hline & Reverse: CCAAGATCCACCTTCTTAGGCTTC \\
\hline \multirow[t]{2}{*}{$G m G T-2 B$ (EF221754) } & Forward: CCTGAACAAATTCTCAGCCACTAC \\
\hline & Reverse: ACAAGTTCTTGAGTCAAGGGACCT \\
\hline \multirow[t]{2}{*}{ GmbZIP62 (DQ787039) } & Forward: GCAACCATTGATTCTCAGTCATCG \\
\hline & Reverse: GTCGAGTGGCCAAATAGTTCCACA \\
\hline \multirow[t]{2}{*}{ GmWRKY54 (DQ322698) } & Forward: GATGAAGGACGACACAAGACTAAG \\
\hline & Reverse: GTGCTGCTGCTGATACTGGGATAA \\
\hline \multirow[t]{2}{*}{ GmERF3 (EU681278) } & Forward: AACGTTCCAAGGTAAATCCACAGG \\
\hline & Reverse: AGCTCCCTTCAAGATAAGGCATCT \\
\hline \multirow[t]{2}{*}{ GmPHD2 (DQ973807) } & Forward: AACAGGTTTTCCGGGACTTCAAGG \\
\hline & Reverse: GCTCCTCGTCATCTTCTTCATCCA \\
\hline \multirow[t]{2}{*}{ GmOLPb (AB370233) } & Forward: TGCGGCAAACTTCGAGATCGTCAA \\
\hline & Reverse: TTACTGGTGGGCGGTACTAGCAGG \\
\hline \multirow[t]{2}{*}{ Gm18SrRNA (X02623) } & Forward: GCATGGGATAACACCACAGGA \\
\hline & Reverse: GGTCGGCATCGTTTATGGTTG \\
\hline
\end{tabular}


to $95^{\circ} \mathrm{C}$ to check for amplification specificity. The efficiency and standard deviation of each primer were given by Bio-Rad CFX manager v1. 6. 541. 1028 on a standard curve generated from a twofold dilution series of one sample at five dilution points for two technical replicates. Baseline and threshold cycle (Ct value) were automatically calculated with default parameters. The primer pairs used in the qRT-PCR are presented in Table 2. The constitutive Actin11 was used as an internal control to normalize the amount of leaf RNAs of soybean plants $(\mathrm{Hu}$ et al. 2009).

\section{Stress tolerance analysis of transgenic plants}

For salt tolerance analysis, seeds of the NT, transformed with empty vector carrying only Bar (EV) and transgenic plants were germinated and grown until vegetative stage 2 (V2-stage, the plant exhibits 2 nodes on the main stem with fully expanded leaves) on wetted rock wools (urmedia, Korea) in the following auto-regulated environment; $25^{\circ} \mathrm{C}$, a long day photoperiod (18 hours light/ 6 hours dark), 60\% humidity. NT, EV and transgenic plants of the V2-stage were transferred to Hoagland's solution and then subsequently acclimated for 72 hours. After the acclimation, the detached leaves of NT, EV and transgenic plants from the first node were floated on $200 \mathrm{mM} \mathrm{NaCl}$ solution for 16 days. The whole NT, EV and transgenic plants with V2-stage were transferred to Hoagland's solution containing the $200 \mathrm{mM} \mathrm{NaCl}$ and grown for 10 days. To confirm the tolerance of osmotic stress, NT, EV and transgenic plants of the V2-stage in rock wool were treated with $40 \mathrm{~mL}$ of $20 \%$ PEG 8000 solution every three days for 21 days.

\section{Determination of ion leakage and chlorophyll content}

The extent of ion leakage from leaves after stress treatment was determined by measuring the conductivity. One gram of leaves was soaked in $10 \mathrm{~mL}$ of distilled water for 24 hours at room temperature. After the incubation, the conductivity of the bathing solution $\left(\mathrm{L}_{\mathrm{t}}\right)$ was measured with a conductivity meter (Model EC-400L, istek, Korea). The leaves returned to the bathing solution, introduced into sealed tubes, and incubated with the bathing solution at $95^{\circ} \mathrm{C}$ for 20 minutes. After cooling to room temperature, the conductivity of the bathing solution $\left(\mathrm{L}_{0}\right)$ was measured again. The $\mathrm{L}_{\mathrm{t}} / \mathrm{L}_{0}$ X $100 \%$ values were calculated and used to evaluate relative electrolyte leakage (Fan et al. 1997).

Table 2. Gene-specific primers used for qRT-PCR.

\begin{tabular}{|c|c|}
\hline Gene name & Primer sequence $\left(5^{\prime}\right.$ to $\left.3^{\prime}\right)$ \\
\hline \multirow[t]{2}{*}{ AtSZF2 (AT2G40140) } & Forward: AAGTGCCTCCTTCGGCATTCATGG \\
\hline & Reverse: CTTGTCTCTACTCGCTGCACCATT \\
\hline \multirow[t]{2}{*}{ GmDREB2 (DQ054363) } & Forward: AGAAGCGAAAGCAGCAGCACCAA \\
\hline & Reverse: ACCCAGCCAGATCCTCGAACG \\
\hline \multirow[t]{2}{*}{ GmGT-2A (EF221753) } & Forward: ACGAGTTGAAGCCTGAGGAGCTGT \\
\hline & Reverse: TGCATCTCTTGTTGCTGTTGCTGT \\
\hline \multirow[t]{2}{*}{ GmGT-2B (EF221754) } & Forward: ACTCCACCTGATCAGAATCCCGAG \\
\hline & Reverse: AGGTACCTGCTGTTGCTGAACACT \\
\hline \multirow{2}{*}{ GmbZIP62 (DQ787039) } & Forward: TCGGCACCAGCTCCCTATTCT \\
\hline & Reverse: TCGGACTCCGTCGTTGTCGT \\
\hline \multirow{2}{*}{ GmWRKY54 (DQ322698) } & Forward: GCCCAGTTATGCCTCGCTCAGTT \\
\hline & Reverse: ATGGTGCTGCTGCGTATACTGGG \\
\hline \multirow[t]{2}{*}{ GmERF3 (EU681278) } & Forward: CCGCCTGACCGCCGATTACC \\
\hline & Reverse: GGCGGCGAAAGCAAAGGGCT \\
\hline \multirow[t]{2}{*}{ GmPHD2 (DQ973807) } & Forward: GGACGAGGAGGAAGAGGTACTGG \\
\hline & Reverse: CCCACATGCCCCACACAAGGTC \\
\hline \multirow[t]{2}{*}{$\mathrm{GmOLPb}(\mathrm{AB} 370233)$} & Forward: GGCACCTGGGGGATGCAACA \\
\hline & Reverse: GGCCCACAGCTTCCTTGCCC \\
\hline \multirow[t]{2}{*}{ Actin11 (BW652479) } & Forward: ATCTTGACTGAGCGTGGTTATTCC \\
\hline & Reverse: GCTGGTCCTGGCTGTCTCC \\
\hline
\end{tabular}


Statistical analysis was also performed using Excel T-Test program to confirm the significance test. Asterisks indicate significant changes compared to NT plants $\left({ }^{*} P<0.05\right.$; $* * P<0.01)$.

Total chlorophyll from leaves of non-transgenic and transgenic plants was isolated in $80 \%$ acetone $(\mathrm{v} / \mathrm{v})$. The chlorophyll content was calculated spectrophotometrically as described by Wu et al. (2008). Statistical analysis was also performed using Excel T-Test program to confirm the significance test. Asterisks indicate significant changes compared to NT plants $(* P<0.05 ; * * P<0.01)$.

\section{RESULTS}

\section{Production of transgenic soybean plants via Agrobacterium-mediated transformation}

To produce transgenic soybean plants expressing $A t S Z F 2$, we constructed a plasmid for soybean transformation. The $A t S Z F 2$ was under the control of the cauliflower mosaic virus $35 \mathrm{~S}$ promoter and the DL-phosphinothricin (PPT) resistance gene was included for selectable marker (Fig. 1). Half seeds of the Korean soybean cultivar (Glycine max L. cv. Kwangankong) were co-cultivated with Agrobacterium

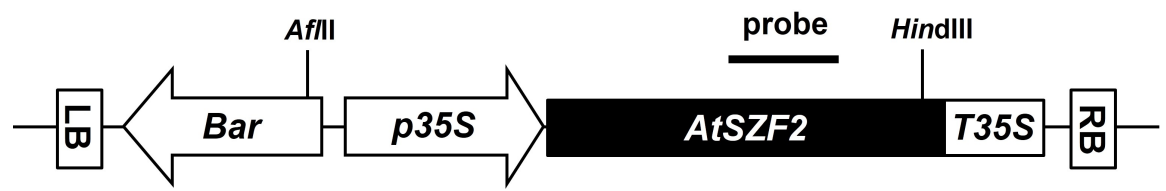

Fig. 1. Schematic representation of the T-DNA of the recombinant binary vector pB2GW7.0-AtSZF2 containing AtSZF2 and Bar used for soybean transformation. LB/RB, left/right T-DNA border sequences; p35S/T35S, CaMV (cauliflower mosaic virus) $35 \mathrm{~S}$ promoter/terminator; Bar, coding region of the DL-phosphinothricin resistance gene. The probe region used for genomic Southern blot analysis presented in Fig. 5 is indicated with solid line. The AflII and HindIII restriction enzyme sites are also marked.

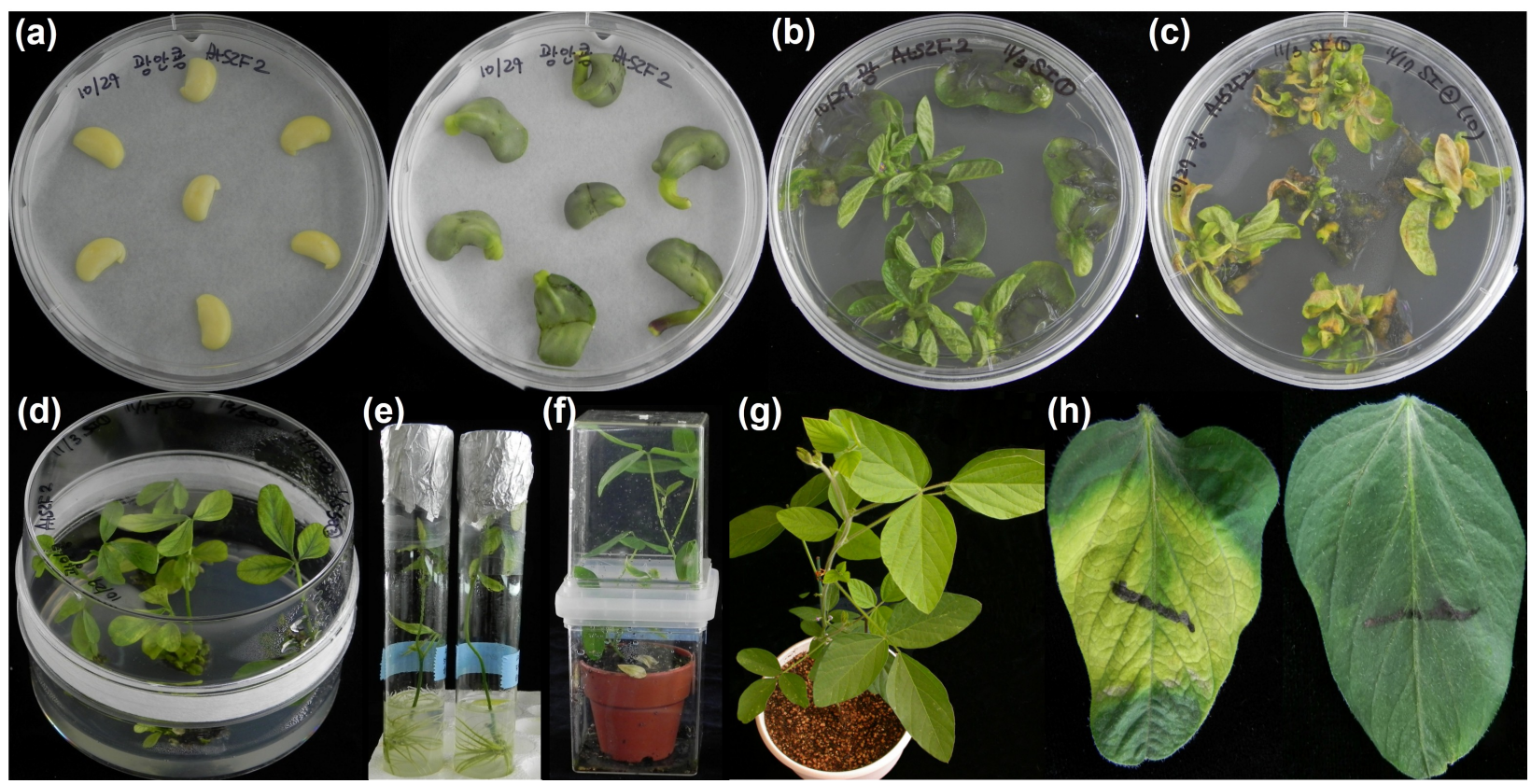

Fig. 2. Production of soybean transgenic plants with AtSZF2 via Agrobacterium-mediated transformation. (a) Half seed explants right after infection (left) and at five day after inoculation (right); (b) Shoot induction medium without PPT; (c) Shoot induction medium containing $10 \mathrm{mg} / \mathrm{L}$ PPT for bar selection for another 14 days; (d) Shoot elongation medium with $5 \mathrm{mg} / \mathrm{L}$ PPT; (e) Rooting medium; (f) Acclimation of putative transgenic plant in a small pot; (g) Transgenic plant in a large pot in a greenhouse; (h) Non-transgenic plant was sensitive (left) and $\mathrm{T}_{0}$ transgenic plant was resistant (right) at five day after PPT leaf painting. 
strains harboring pB2GW7.0-AtSZF2 for 5 days (Fig. 2a). Before co-cultivation, three additional treatments including dipping with high concentration of Agrobacterium solution, sonication and vacuum were applied to soybean transformation with half-seed. The explants were placed on the shoot induction media (SIM) without the PPT, and then normal shoot formation and proliferation were observed (Fig. 2b). During two weeks of selection on SIM with 10 $\mathrm{mg} / \mathrm{L}$ PPT, most of primary shoots became necrotic (Fig. 2c). After four weeks on SIM, cotyledons were removed completely, and explants were transferred to shoot elongation media (SEM) with $5 \mathrm{mg} / \mathrm{L}$ PPT (Fig. 2d). The elongated shoots after four to six weeks were transferred to root induction medium (RIM) (Fig. 2e). Roots were formed properly when elongated shoots were chosen with relatively larger size of leaves. Rooted plantlets were transplanted to a small pot containing the mixture of soil and placed into a majenta jar for acclimation (Fig. 2f). Well-grown plants $\left(T_{0}\right)$ were transplanted in the large pots and transferred to the greenhouse (Fig. 2g). Herbicide-resistance of the transgenic soybean plants was tested at 5-7 days after the herbicide application with $100 \mathrm{mg} / \mathrm{L}$ PPT. The primary determination whether the regenerated plants is positive or negative was decided by leaf painting (Fig. $2 \mathrm{~h}$ ). With this construct, the whole procedure, starting from seed preparation to seed harvest, has taken about 7 months. A total of 16 transgenic soybean plants were generated with a transformation efficiency of about $4 \%$ from 3 batches of experiments, in which 150 soybean seeds were used for each time (data not shown). All these plants were grown in the greenhouse, and $T_{1}$ seeds were harvested.

\section{Analysis of transgene integration and expression}

To verify transgene integration in $35 \mathrm{~S}:: A t S Z F 2$ transformants, genomic DNAs from all putative $\mathrm{T}_{0}$ transformants were isolated and subjected to PCR analysis using primers designed to amplify the coding sequences of the AtSZF2 and Bar, respectively. To identify T-DNA insertions into

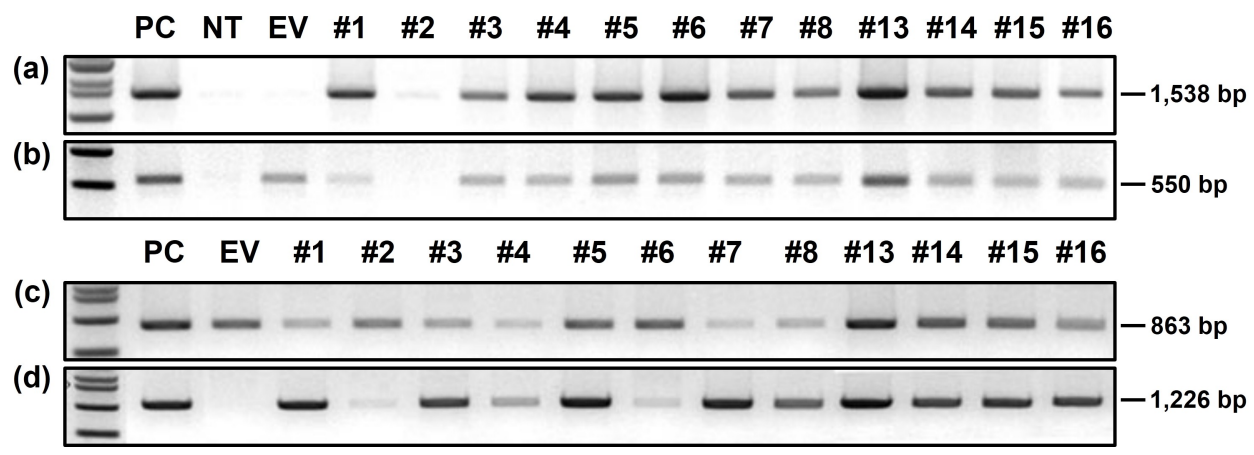

Fig. 3. Confirmation of $A t S Z F 2$ transformants using PCR amplification of genomic DNA samples extracted from $\mathrm{T}_{0}$ transgenic leaf tissues. (a) AtSZF2; (b) Bar; (c) the DNAs between left border (LB) and Bar; (d) the DNAs between $A t S Z F 2$ and right border (RB); NT, non-transgenic plant as a negative control; PC, binary vector carrying $A t S Z F 2$ and Bar as a positive control; EV, transformed with empty vector carrying only Bar; \#1 \#16, $\mathrm{T}_{0} A t S Z F 2$ transgenic lines.

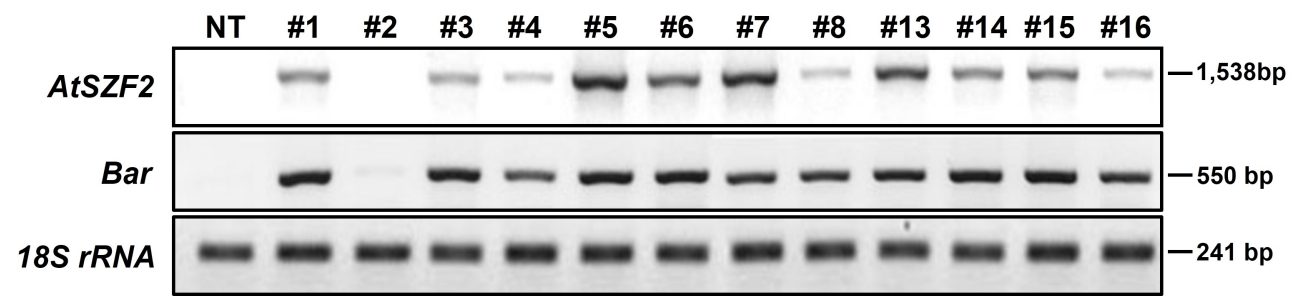

Fig. 4. Expression of $A t S Z F 2$ and $B a r$ in $\mathrm{T}_{0}$ transgenic plant. Total RNA was extracted from $\mathrm{T}_{0}$ plants, and then analyzed by RT-PCR with $18 S$ rRNA as a quantitative control. NT, non-transgenic plant; \#1 \#16, $\mathrm{T}_{0}$ AtSZF2 transgenic lines. 
the plant genome, the intactness of the introduced gene regions was examined by further genomic PCR analysis to amplify the both end regions of the vector construct (Fig. 3). Almost all of putative transformants were introduced successfully as a complete transgene. One (line \#2) out of 12 transgenic lines had missing region of the integrated vector sequences. To analyze the transcript levels of $A t S Z F 2$, RT-PCR was performed using RNAs extracted from $\mathrm{T}_{0}$ transgenic soybean (Fig. 4). Both AtSZF2 and Bar transcript levels were investigated from 12 transgenic lines. As shown in Fig. 4, these genes were expressed in all the lines tested only except in line \#2.

For further analysis, four representative transgenic lines were selected due to their phenotype and harvested seeds. To determine the number of insertion events in the selected four transgenic lines, genomic Southern blot analysis was performed using AtSZF2 probe. Genomic DNAs were isolated from $\mathrm{NT}$ and $\mathrm{T}_{1}$ transgenic plants (\#4, \#6,\#13 and \#15), and $3 \mu \mathrm{g}$ of the genomic DNA was digested with HindIII and $A f l I \mathrm{I}$ and fractionated on $0.8 \%$ agarose gel. The resulting restriction bands shown in the Southern blot analysis confirmed the presence of the AtSZF2 gene in the $\mathrm{T}_{1}$ soybean (Fig. 5). Line \#6 showed one copy while lines

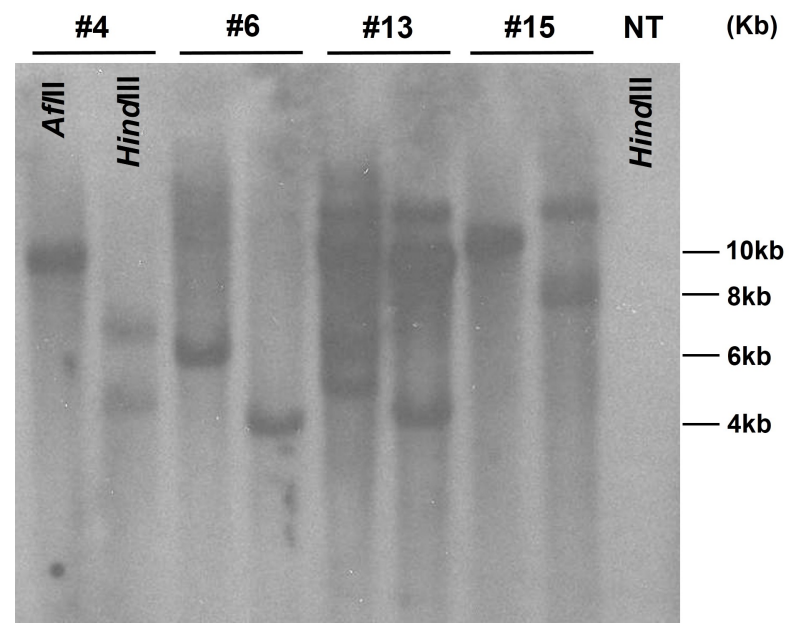

Fig. 5. Genomic Southern blot analysis of AtSZF2 transgenic soybean plants. Three micrograms of genomic DNAs from leaf tissues were digested with AflII and HindIII, and hybridized with probe AtSZF2. The DNA molecular size markers are indicated on the right. NT, non-transgenic plant; \#4, \#6, \#13 and $\# 15, \mathrm{~T}_{1} A t S Z F 2$ transgenic lines.
$\# 4$, \#13 and \#15 showed either two or three copies when digested with HindIII and AflII. Two transgenic lines (\#4 and \#6) that contained single or two copy of insertions of the transgene were chosen for the further functional analysis of introduced AtSZF2 gene.

\section{Response of transgenic soybean plants to salt stress}

To investigate whether the expression of AtSZF2 was correlated with stress tolerance in transgenic soybean plants, 1-node detached leaves of NT, EV and $\mathrm{T}_{2}$ transgenic

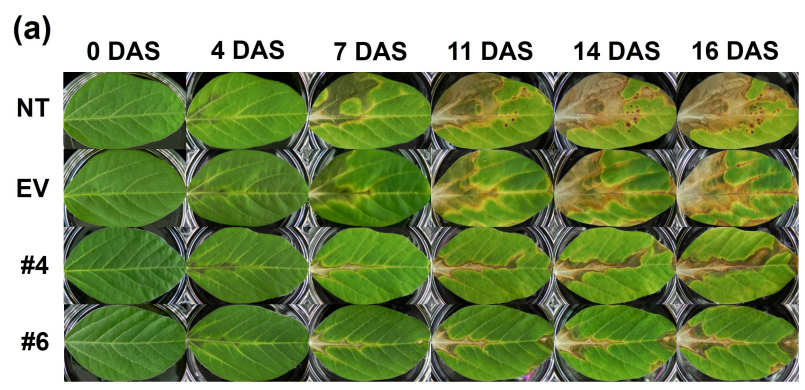

(b)

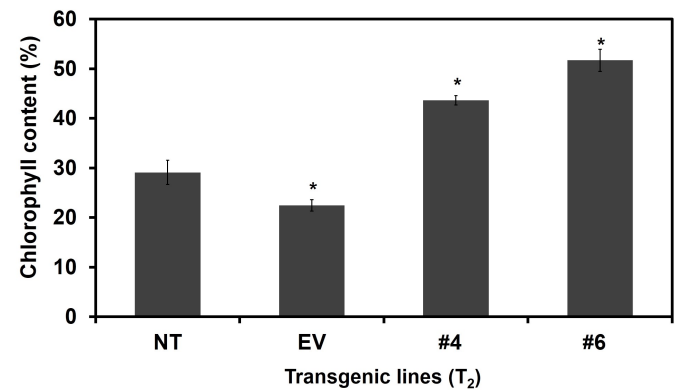

Fig. 6. Salt tolerance analysis of the detached leaves in NT and AtSZF2 $\mathrm{T}_{2}$ transgenic plants (\#4 and \#6). (a) Comparison of NT, EV and transgenic plants exposed to salt stress. Plants were grown until vegetative stage 2 on wetted rock wool under 16 hours of light and 8 hours of darkness at $24^{\circ} \mathrm{C}$ and then 1-node leaves were floated on $200 \mathrm{mM}$ $\mathrm{NaCl}$ solution for 16 days. The photographs showed representative leaves at indicated days after salt treatment. (b) The chlorophyll contents were measured using the 1-node leaves of NT, $\mathrm{EV}$ and transgenic plants after 16 day of salt stress. NT, non-transgenic plant; EV, transformed with empty vector carrying only Bar; \#4 and \#6; $\mathrm{T}_{2}$ transgenic lines, DAS; day after salt stress. Error bars indicated mean \pm standard deviation. Asterisks indicated significant differences compared to the NT plant $(* P<0.05 ; * * P<0.01)$. 
lines (\#4 and \#6) were floated on $200 \mathrm{mM} \mathrm{NaCl}$ solution for 16 days (Fig. 6). After 16 days of the salt stress, leaves of NT and EV plants turned into yellow-green with a concomitant loss of chlorophyll, and showed necrosis, whereas leaves of transgenic lines continuously remained green (Fig. 6a). The chlorophyll contents in the leaves of NT, EV and transgenic plants were measured after high salt treatment. The chlorophyll contents in the leaves of transgenic lines were higher than those of the NT and EV plants floated on $200 \mathrm{mM} \mathrm{NaCl}$ solution with statistical significance $(P<0.05)$ (Fig. 6b). The result indicates that transgenic lines (\#4 and \#6) are more tolerant to high salt stress. The seedlings of NT, EV and transgenic plants were further subjected to salt stress with $200 \mathrm{mM} \mathrm{NaCl}$ solution, and the phenotypic changes were observed (Fig. 7). NT, $\mathrm{EV}$ and transgenic plants were grown until vegetative stage 2 on wetted rock wool. No significant change was observed under normal growth condition when compared with NT and EV plants. Then, the V2-stage plants were soaked in $200 \mathrm{mM} \mathrm{NaCl}$ solution for 10 days. After 5 day of salt stress, 2nd-node leaves of NT and EV gradually withered and the color changed to yellow-green from the edge of the leaves while transgenic lines remained green. Phenotypic differences between NT and transgenic plants clearly (a)

NT

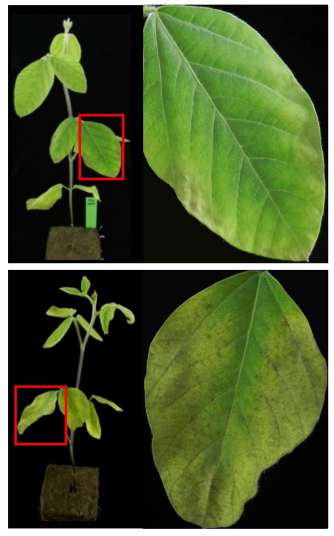

(b)

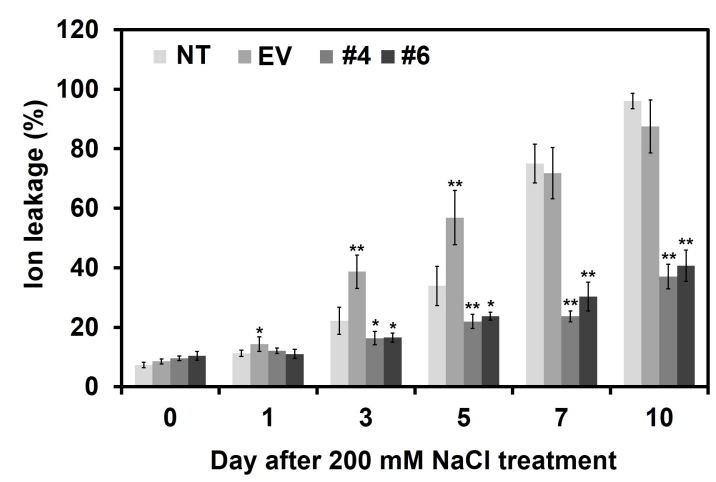

\#4

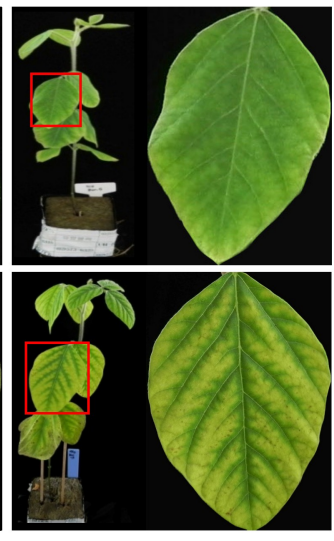

(c)

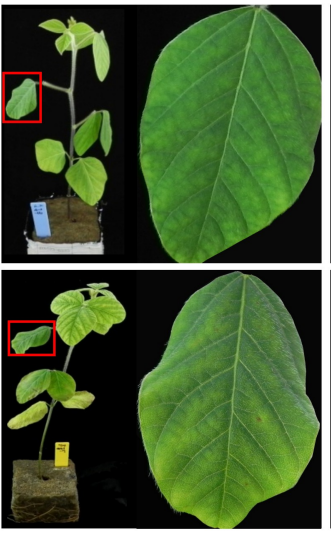

\#6
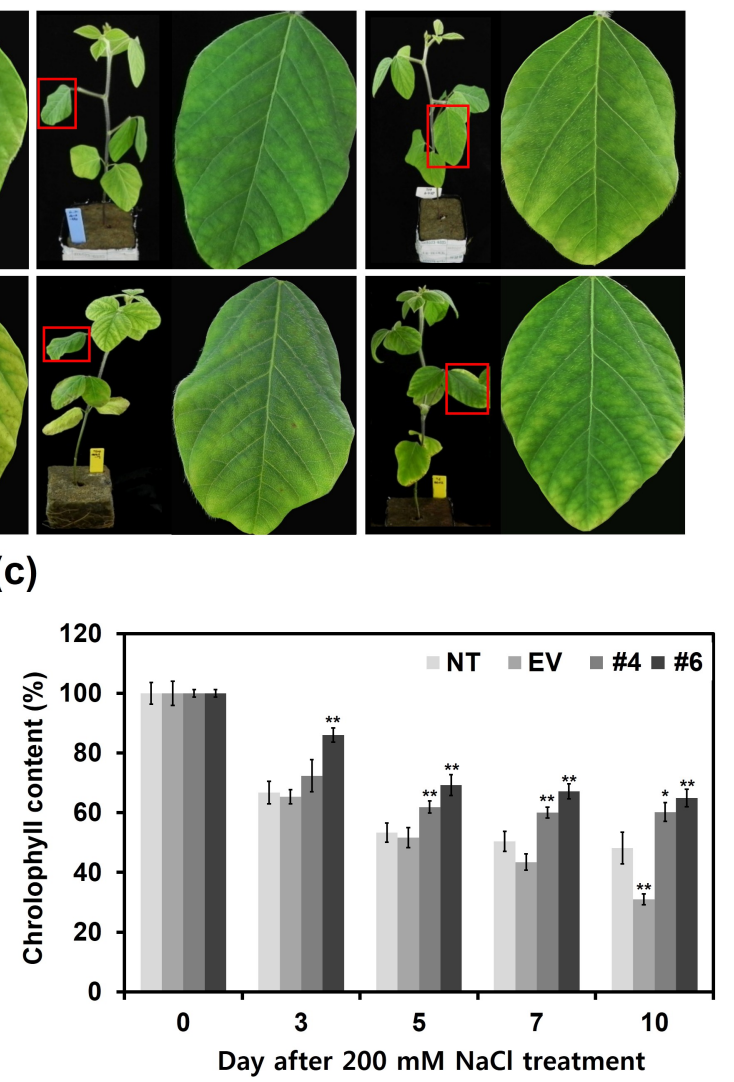

Fig. 7. Salt tolerance analysis of the whole plant in NT and AtSZF2 $\mathrm{T}_{2}$ transgenic plants (\#4 and \#6). (a) Comparison of NT, EV and transgenic plants exposed to salt stress. Plants were grown until vegetative stage 2 (V2) on wetted rock wool under 16 hours of light and 8 hours of darkness at $24^{\circ} \mathrm{C}$ and then V2 plants were soaked in $200 \mathrm{mM}$ $\mathrm{NaCl}$ solution for 10 days. The photographs were taken at 5 and 10 day after salt treatment. (b, c) Ion leakage and chlorophyll contents were measured using 2-node leaves of NT, EV and transgenic plants at the indicated day after salt treatment. NT, non-transgenic plant; EV, transformed with empty vector carrying only Bar; \#4 and \#6; $\mathrm{T}_{2}$ transgenic lines, DAS; day after salt treatment. Error bars indicated mean \pm standard deviation. Asterisks indicated significant differences compared to the NT plant $(* P<0.05 ; * * P<0.01)$. 
appeared after 10 days of salt stress. The leaves of NT and EV showed severe wilting and chlorosis, followed by color change into yellow-green, whereas the transgenic lines were slowly etiolated from the edge of the leaves which indicates relative tolerance to salt stress (Fig. 7a). The enhanced salt tolerance of the transgenic lines was further verified by measuring changes in ion leakage and chlorophyll content (Fig. 7b and c). High salt stress caused a remarkable increase in ion leakage from leaves of NT and EV plants. In transgenic lines, ion leakage increased under high salt stress, but the degree was significantly weaker
$(P<0.01)$ than in NT and EV plants. In addition, chlorophyll contents of leaves in transgenic lines were significantly higher $(P<0.05$ in line $\# 4$ and $P<0.01$ in line \#6) than those of NT and EV leaves after 10 day of salt treatment. These results indicate that the transgenic lines were less affected by salt stress and led to enhanced salt tolerance due to the reduction of cell membrane damage.

\section{Response of transgenic soybean plants to osmotic stress}

High salt environment generates osmotic stress on plants that is caused by reduced water availability in soil (Ren $e t$ (a)

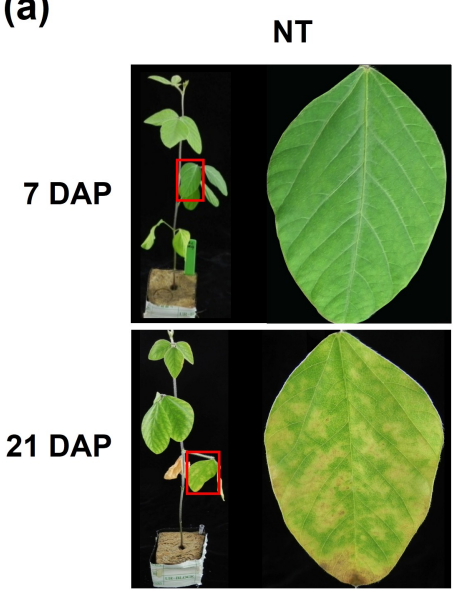

(b)

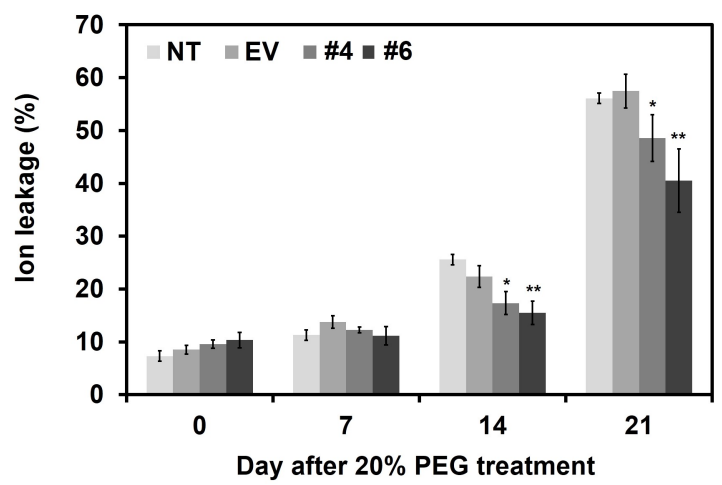

\#4

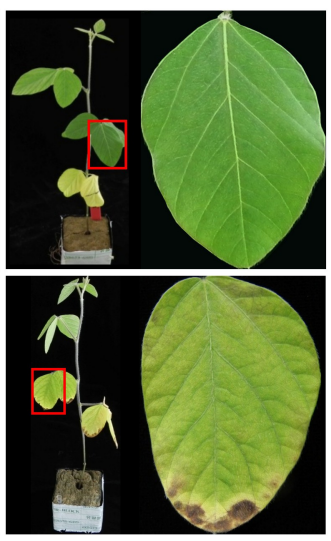

(c)
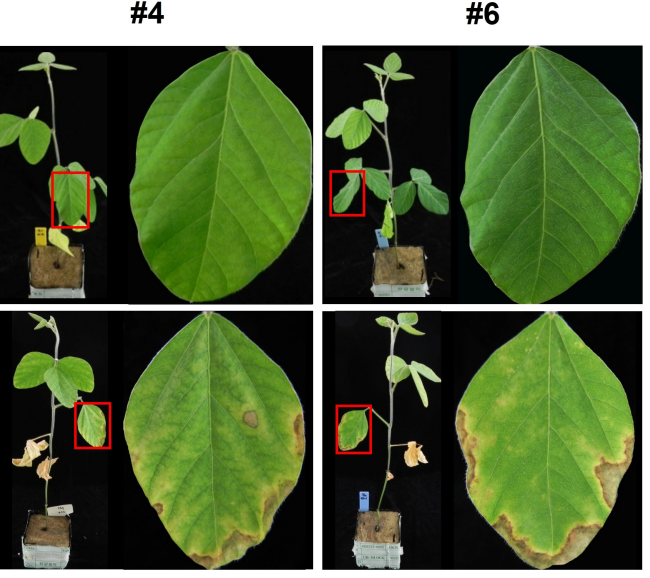

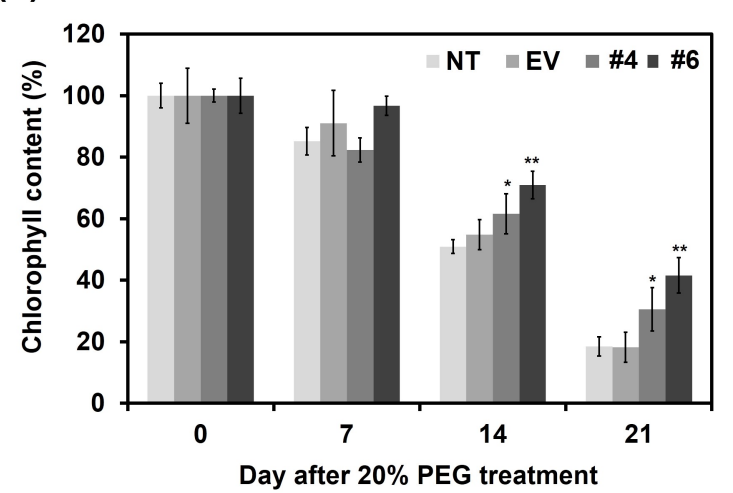

Fig. 8. Drought tolerance analysis of the whole plants in NT and AtSZF2 $\mathrm{T}_{2}$ transgenic plants. (a) Comparison of NT, EV and transgenic plants exposed to drought stress. Plants were grown until vegetative stage 2 (V2) on wetted rock wool under 16 hours of light and 8 hours of darkness at $24^{\circ} \mathrm{C}$ and then $\mathrm{V} 2$ plants were poured $40 \mathrm{~mL}$ of $20 \%$ PEG solution into the rock wool every three days for 21 days. The photographs were taken at 7 and 21 day after 20\% PEG treatment. (b, c) Ion leakage and chlorophyll contents were measured using 2-node leaves of NT, EV and transgenic plants at the indicated day after 20\% PEG treatment. NT, non-transgenic plant; EV, transformed with empty vector carrying only Bar; \#4 and \#6; T2 transgenic lines, DAP; day after 20\% PEG treatment. Error bars indicated mean \pm standard deviation. Asterisks indicated significant differences compared to the NT plant $\left({ }^{*} P<0.05 ; * * P<0.01\right)$. 
al. 2016). To study the response of transgenic plants to osmotic stress, we treated seedlings of NT, EV and $\mathrm{T}_{1}$ transgenic plants (line \#4 and \#6) with 20\% PEG solution for 21 days (Fig. 8). None of the plants showed any apparent differences after 7 days, but the leaves of NT and EV plants began to wither after 14 days. After 21 day of $20 \%$ PEG treatment, leaves of NT and EV plants showed noticeable damage with necrosis, compared to transgenic plants (Fig. 8a). We also performed physiological analysis to evaluate the ion leakage and chlorophyll content with NT, EV and transgenic leaves after 20\% PEG treatment. As shown in Fig. 8b, the extent of ion leakage ranged from $7.31 \%$ to $10.35 \%$ in all the plants under normal conditions. With the osmotic stress condition, the extent of ion leakage increased gradually, but was lower in the transgenic lines after 14 and 21 day of $20 \%$ PEG treatment. The ion leakage ratio was $50 \%$ higher than untreated values after 21 days in the NT and EV leaves. In contrast, transgenic lines showed $30 \%$ higher in ion leakage, compared to the untreated $(P<0.05$ in line $\# 4$ and $P<0.01$ in line \#6). There was no statistically significant difference in chlorophyll content among the NT, EV and transgenic plants under normal growth condition. However, the chlorophyll content in leaves significantly decreased by 21 day of $20 \%$ PEG treatment. Moreover, the chlorophyll loss in transgenic plants was significantly lower than that in the NT and EV plants $(P<0.05$ in line $\# 4$ and $P<0.01$ in line \#6) (Fig. 8c). According to the results above, it is clear that the damage of cell membrane was prevented in transgenic plants and the chlorophyll content was maintained because of transgene expression.

\section{Expression analysis of abiotic stress responsive genes in transgenic soybean plants}

To investigate the expression of various stress-related genes in transgenic soybean plants, a number of genes were selected as candidate target genes for RT-PCR and qRT-PCR analysis (Fig. 9). The transcript levels of $\mathrm{ABA} /$ stress responsive genes were enhanced in transgenic lines, compared to NT and EV plants. The expression of the GmDREB2 (Chen et al. 2007), an A-5 subgroup gene of the DREB (dehydration-responsive element-binding protein) subfamily, increased in the transgenic lines. Strong enhancement of GmGT-2A and GmGT-2B (Xie et al. 2009) transcript level was also observed. These transcription factors were among Trihelix family and known as GT factors (DNA binding proteins with specificity for GT-elements). An increase in the GmbZIP62 (Liao et al.
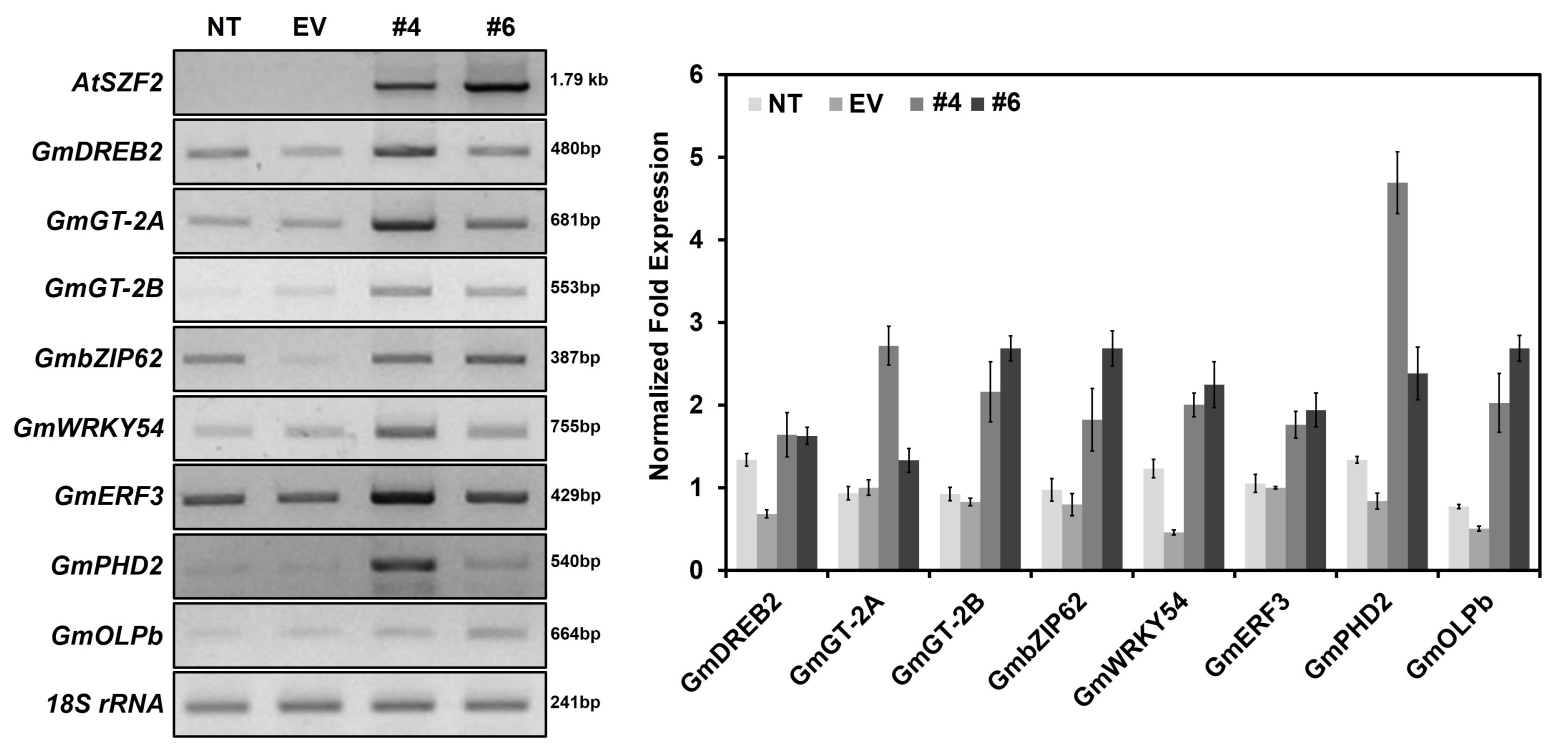

Fig. 9. Expression of abiotic stress-responsive genes in $\mathrm{NT}$ and $\mathrm{T}_{2}$ AtSZF2 transgenic plants (\#4 and \#6) using RT-PCR (left) and qRT-PCR (right). NT, non-transgenic plant; EV, transformed with empty vector carrying only Bar; \#4 and \#6 $\mathrm{T}_{2}$ transgenic lines. The soybean $18 S$ rRNA and Actin11 were used as quantitative controls. 
2008) was also observed in the transgenic plants. The RNA level of the abiotic stress responsive genes, ethylene response factor gene GmERF3 (Zhang et al. 2009) and WRKY-type transcription factor gene GmWRKY54 (Zhou et al. 2008) barely increased. In case of the osmotin-like protein b isoform gene $\mathrm{GmOLPb}$ (Tachi et al. 2009) and plant-homeo-domain gene GmPHD2 (Wei et al. 2009), their expressions enhanced significantly in the transgenic plant. In summary, introduction of AtSZF2 resulted in the modulation of $\mathrm{ABA} /$ stress responsive gene expression in transgenic soybean plants and make them tolerant against salt stress.

\section{DISCUSSION}

To improve the production of successful soybean transgenic plants, previously reported half-seed method (Paz et al. 2006) with modification was used in this experiment. We have proven the efficiency of transformation with dipping with high concentration of Agrobacterium solution, sonication and vacuum during the inoculation procedure (Kim et al. 2012; Kim et al. 2013; Kim et al. 2016). Our method also included the addition of thiol compound including sodium thiosulfate, L-cysteine and dithiothreitol (DTT) in co-cultivation stage to prevent the cell damage. We believed that these thiol compounds could reduce apoptotic cell response after wounding and Agro-infection, and resulted in the increased early organ formation during shoot induction and elongation stages of regeneration. Our soybean genotype, Kwangankong, especially well adopted with thiol compound. This modified protocol enabled us to establish the stable Agrobacterium-mediated soybean transformation with less time consumption.

Many stress-related genes have been identified and characterized for their roles (Gelvin 2005; He et al. 2010; Zhang et al. 2010; Subramanyam et al. 2011; Bhuiyan et al. 2011; Li et al. 2011; Movahedi et al. 2012; Yarra et al. 2012). The goal of our study was to investigate the potential of the salt stress tolerant candidate gene in major crop such as soybean. Among many candidate genes, $\mathrm{CCCH}$-type zinc finger protein which has shown to be associated with
RNA metabolism (Bai and Tolias 1996; Carballo et al. 1998; Lai et al. 2006; Hurt et al. 2009) and known to be involved in abiotic and biotic stresses could be a good gene source for salt stress tolerance. In previous report, GHZFP1, a $\mathrm{CCCH}$-type zinc finger protein from cotton, was found to enhance the tolerance of salt stress (Guo et al. 2009). Salt stress-inducible zinc finger protein 1 (AtSZF1) and AtSZF2 were also reported for their function in regulating the resistance of Arabidopsis plants to oxidative and salt stress response, respectively (Sun et al. 2007; Huang et al. 2011). With such a previous study, we now need to introduce this gene into crop plants for the practical use in agriculture. In this study, AtSZF2 was transformed into soybean by Agrobacterium-mediated transformation to produce salt stress tolerant soybean. Transgenic plants showed normal growth under high salt condition, while leaves of NT and EV plants became wrinkled and discolored, and died eventually. It is well known that plants with tolerance to high salinity and drought stress have better ability to survive in stressful environmental conditions due to the reduced alteration of cell membrane permeability during osmotic adjustment in high salinity condition. This result suggests that the effect of AtSZF2 increased the ability of transgenic plants to counteract the damage of salinity stress on endogenous cell membranes, which allowed the transgenic plants to survive under the stress conditions. The chlorophyll change is also considered as an important factor for the physiological response to salt stress in plants. The maintenance of higher chlorophyll content in transgenic plants could lead to their enhanced salt tolerance. Even though EV is a little different from control, it is clear that the salt tolerance is from gene itself. With all the evidence of physiological response in transgenic plants, it is clear that the enhanced tolerance of high salinity is triggered by introduced AtSZF2 in transgenic soybean. Therefore, genetic transformation will be a powerful tool to enhance the tolerance to abiotic stresses in the crop breeding.

Soybean is considered as a salt-sensitive crop, which is severely affected by salt stress that is harmful to plant growth. Salt stress significantly reduces plant height and leaf size, decreases seed quality and chlorophyll content in plant. Finally, high soil salinity considerably affects seed yield, which is an important factor in crop productivity (Ren 
et al. 2016). In this study, we introduced AtSZF2 gene from Arabidopsis into soybean using Agrobacterium-mediated transformation in order to improve salt tolerance of soybean. The result obtained in our study suggests that the overexpression of $A t S Z F 2$ in soybean may provide an approach for crop improvement through genetic transformation.

\section{ACKNOWLEDGEMENTS}

This work was supported by the Next-Generation BioGreen 21 Program (Code PJ011150), Rural Development Administration, and Korea Institute of Planning and Evaluation for Technology in Food, Agriculture, Forestry and Fisheries (Code 112124-5), Republic of Korea.

\section{REFERENCES}

Bai C and Tolias PP. 1996. Cleavage of RNA hairpins mediated by a developmentally regulated $\mathrm{CCCH}$ zinc finger protein. Mol. Cell. Biol. 16: 6661-6667.

Bhuiyan MSU, Min SR, Jeong WJ, Sultana S, Choi KS, Song WY, Lee Y, Lim YP, Liu JR. 2011. Overexpression of a yeast cadmium factor 1 (YCF1) enhances heavy metal tolerance and accumulation in Brassica juncea. Plant Cell Tiss. Organ Cult. 105: 85-91.

Carballo E, Lai WS, Blackshear PJ. 1998. Feedback inhibition of macrophage tumor necrosis factor- $\alpha$ production by tristetraprolin. Science 281: 1001-1005.

Chen M, Wang QY, Cheng XG, Xu ZS, Li LC. 2007. $G m D R E B 2$, a soybean DRE-binding transcription factor, conferred drought and high-salt tolerance in transgenic plants. Biochem. Biophys. Res. Commun. 353: 299-305.

Fan L, Zheng S, Wang X. 1997. Antisense suppression of phospholipase D alpha retards abscisic acid- and ethylenepromoted senescence of postharvest Arabidopsis leaves. Plant Cell 9: 2183-2196.

Flowers TJ. 2004. Improving crop salt tolerance. J. Exp. Bot. 55: $307-319$

Gelvin SB. 2005. Agricultural biotechnology: gene exchange by design. Nature. 433: 583-584.

Guo YH, Yu YP, Wang DW, Wu CA, Yang GD, Huang JG, et al. 2009. GhZFP1, a novel CCCH-type zinc finger protein from cotton, enhances salt stress tolerance and fungal disease resistance in the transgenic tobacco by interacting with GZIRD21A and GZIPR5. New Phytol. 183: 62-75.

Hall TMT. 2005. Multiple modes of RNA recognition by zinc finger proteins. Curr. Opin. Struct. Biol. 15: 367-373.

Hasegawa PM, Bressan RA, Zhu JK, Bohnert HJ. 2000. Plant cellular and molecular response to high salinity. Annu. Rev. Plant Physiol. Plant Mol. Biol. 51: 463-499.

He C, Yang A, Zhang W, Gao Q, Zhang J. 2010. Improved salt tolerance of transgenic wheat by introducing beta gene for glycine betaine synthesis. Plant Cell Tiss. Organ Cult. 101: 65-78.

Hinchee MAW, Connor-Ward DV, Newell CA, McDonnell RE, Sato SJ, Gasser CS, et al. 1988. Production of transgenic soybean plants using Agrobacterium-mediated DNA transfer. Nat. Biotechnol. 6: 915-922.

Hu R, Fan C, Li H, Zheng Q, Fu YF. 2009. Evaluation of putative reference genes for gene expression normalization in soybean by quantitative real-time RT-PCR. BMC Mol. Biol. 10: 93.

Huang P, Chung MS, Ju HW, Na HS, Lee DJ, Cheong HS, et al. 2011. Physiological characterization of the Arabidopsis thaliana Oxidation-related Zinc Finger 1, a plasma membrane protein involved in oxidative stress. J. Plant. Res. 124: 699-705.

Hurt JA, Obar RA, Zhai B, Farny NG, Gygi SP, Silver PA. 2009. A conserved CCCH-type zinc finger protein regulates mRNA nuclear adenylation and export. J. Cell Biol. 185: 265-277.

Karimi M, Inze' D, Depicker A. 2002. Gateway ${ }^{\mathrm{TM}}$ vectors for Agrobacterium-mediated plant transformation. Trends Plant Sci. 7: 193-195.

Kim AR, Lim H, Cho JI, Kim CK, Ji SU, Park SC, et al. 2015. Overexpression of BrTSR53 gene improved tolerance of rice plant to salt stress. Plant Breed. Biotech. 3: 376-383.

Kim HJ, Kim MJ, Pak JH, Jung HW, Choi HK, Lee YH, et al. 2013. Characterization of SMV resistance of soybean produced by genetic transformation of $S M V-C P$ gene in RNAi. Plant Biotechnol. Rep. 7: 425-433.

Kim HJ, Kim MJ, Pak JH, Im HH, Lee DH, Kim KH, et al. 2016. RNAi-mediated soybean mosaic virus (SMV) resistance of a Korean soybean cultivar. Plant Biotechnol. Rep. 10: 257-267.

Kim MJ, Kim JK, Kim HJ, Pak JH, Lee JH, Kim DH, et al. 
2012. Genetic modification of the soybean to enhance the $\beta$-carotene content through seed-specific expression. PLoS ONE 10: e48287.

Kwon TR, Kim KH, Yoon HJ, Lee SK, Kim BK, Siddiqui ZS. 2015. Phenotyping of plants for drought and salt tolerance using infra-red thermography. Plant Breed. Biotech. 3: 299-307.

Lai WS, Parker JS, Grissom SF, Stumpo DJ, Blackshear PJ. 2006. Novel mRNA targets for tristetraprolin (TTP) identified by global analysis of stabilized transcripts in TTP-deficient fibroblasts. Mol. Cell. Biol. 26: 9196-9208.

Li M, Lin X, Li H, Pan X, Wu G. 2011. Overexpression of AtNHX5 improves tolerance to both salt and water stress in rice (Oryza sativa L.). Plant Cell Tiss. Organ Cult. 107: 283-293.

Liao Y, Zou HF, Wei W, Hao YJ, Tian AG, Huang J, et al. 2008. Soybean GmbZIP44, GmbZIP62 and GmbZIP78 genes function as negative regulator of ABA signaling and confer salt and freezing tolerance in transgenic Arabidopsis. Planta 228: 225-240.

Meurer CA, Dinkins RD, Collins GB. 1998. Factors affecting soybean cotyledonary node transformation. Plant Cell Rep. 18: 180-186.

Miller J, McLachlan AD, Klug A. 1985. Repetitive zinc-binding domains in the protein transcription factor IIIA from Xenopus oocytes. EMBO J. 4: 1609-1614.

Movahedi S, Tabatabaei BES, Alizade H, Ghobadi C, Yamchi A, Khaksar G. 2012. Constitutive expression of Arabidopsis $D R E B 1 B$ in transgenic potato enhances drought and freezing tolerance. Biol. Plant. 56(1): 37-42.

Munns R and Tester M. 2008. Mechanisms of salinity tolerance. Annu. Rev. Plant Biol. 59: 651-681.

Olhoft PM, Flagel LE, Donovan CM, Somers DA. 2003. Efficient soybean transformation using hygromycin $\mathrm{B}$ selection in the cotyledonary-node method. Planta 216: 723-735.

Paz MM, Martinez JC, Kalvig AB, Fonger TM, Wang K. 2006. Improved cotyledonary node method using an alternative explant derived from mature seed for efficient Agrobacterium-mediated soybean transformation. Plant Cell Rep. 25: 206-213.

Phang TH, Shao G, Lam HM. 2008. Salt tolerance in soybean. J. Integr. Plant Biol. 50: 1196-1212.

Ren S, Lyle C, Jiang G, Penumala A. 2016. Soybean salt tolerance 1 (GmST1) reduces ROS Production, enhances ABA sensitivity, and abiotic stress tolerance in Arabidopsis thaliana. Front Plant Sci 7: 445.

Shinozaki K and Yamaguchi-Shinozaki K. 2000. Gene networks involved in drought stress response and tolerance. J. Exp. Bot. 58: 221-227.

Shinozaki K, Yamaguchi-Shinozaki K, Seki M. 2003. Regulatory network of gene expression in the drought and cold stress responses. Curr. Opin. Plant Biol. 6: 410-417.

Subramanyam K, Sailaja KV, Subramanyam K, Rao DM, Lakshmidevi K. 2011. Ectopic expression of an osmotin gene leads to enhanced salt tolerance in transgenic chilli pepper (Capsicum annum L.). Plant Cell Tiss. Organ Cult. 105: 181-192.

Sun J, Jiang H, Xu Y, Li H, Wu X, Xie Q, Li C. 2007. The $\mathrm{CCCH}$-type zinc finger proteins AtSZF1 and AtSZF2 regulate salt stress responses in Arabidopsis. Plant Cell Physiol. 48: 1148-1158.

Tachi H, Fukuda-Yamada K, Kojima T, Shiraiwa M, Takhara H. 2009. Molecular characterization of a novel soybean gene encoding a neutral PR-5 protein induced by high-salt stress. Plant Physiol. Biochem. 47: 73-79.

Tester $\mathrm{M}$ and Davenport R. 2003. $\mathrm{Na}^{+}$tolerance and $\mathrm{Na}^{+}$ transport in higher plants. Ann. Bot. 91: 503-527.

Wei W, Huang J, Hao YJ, Zou HF, Wang HW, Zhao JY, et al. 2009. Soybean GmPHD-type transcription regulators improve stress tolerance in transgenic Arabidopsis plants. PLoS ONE 4: e7209.

Wu C, Niu Z, Tang Q, Huang W. 2008. Estimating chlorophyll content from hyperspectral vegetation indices: Modeling and validation. Agri. For. Meteorol. 148: 1230-1241.

Xie ZM, Zou HF, Lei G, Wei W, Zhou QY, Niu CF, et al. 2009. Soybean Trihelix transcription factors GmGT-2A and GmGT-2B improve plant tolerance to biotic stresses in transgenic Arabidopsis. PLoS ONE 4: e6898.

Xiong L, Schumaker KS, Zhu JK. 2002. Cell signaling during cold, drought, and salt stress. Plant Cell 14: S165-S183.

Yarra R, He SJ, Abbagani S, Ma B, Bulle M, Zhang WK. 2012. Overexpression of a wheat $\mathrm{Na}^{+} / \mathrm{H}^{+}$antiporter gene (TaNHX2) enhances tolerance to salt stress in transgenic tomato plants. Plant Cell Tiss. Organ Cult. 111: 49-57.

Zhang G, Chen M, Li L, Xu Z, Chen X, Guo J, Ma Y. 2009. Overexpression of the soybean GmERF3 gene, an AP2/ERT type transcription factor for increased tolerance 
to salt, drought, and diseases in transgenic tobacco. J. Exp. Bot. 60: 3781-3796.

Zhang H, Liu W, Wan L, Li F, Dai L, Li, D, et al. 2010. Functional analyses of ethylene response factor JERF3 with the aim of improving tolerance to drought and osmotic stress in transgenic rice. Transgenic Res. 19: 809-818.

Zhou QY, Tian AG, Zou HF, Xie ZM, Lei G, Hung J, et al.
2008. Soybean WRKY-type transcription factor genes, GmWRKY13, GmWRKY21, and GmWRKY54, confer differential tolerance to abiotic stresses in transgenic Arabidopsis plants. Plant Biotechnol. J. 6: 486-503.

Zhu JK. 2002. Salt and drought stress signal transduction in plants. Annu. Rev. Plant Biol. 53: 247-273.

Zhu JK. 2003. Regulation of ion homeostasis under salt stress. Curr. Opin. Plant Biol. 6: 441-445. 